\title{
Silicon Carbide Nanotube Oxidation at High Temperatures
}

\author{
Nadia Ahlborg \\ The Ohio State University, Columbus, Ohio 43210 \\ Dongming Zhu \\ NASA Glenn Research Center, Cleveland, Ohio 44135
}

36th International Conference on Advanced Ceramics and Composites

Daytona Beach, Florida, USA

January 22-27, 2012 


\section{Abstract}

Silicon Carbide Nanotubes (SiCNTs) have high mechanical strength and also have many potential functional applications. In this study, SiCNTs were investigated for use in strengthening high temperature silicate and oxide materials for high performance ceramic nanocomposites and environmental barrier coating bond coats. The high temperature oxidation behavior of the nanotubes was of particular interest.

The SiCNTs were synthesized by a direct reactive conversion process of multiwall carbon nanotubes and silicon at high temperature. Thermogravimetric analysis (TGA) was used to study the oxidation kinetics of SiCNTs at temperatures ranging from $800^{\circ} \mathrm{C}$ to $1300^{\circ} \mathrm{C}$. The specific oxidation mechanisms were also investigated. 


\section{Experimental: SiCNT Nanotube and Nanotube Coating Processing}

- $\quad$ SiCNTs were synthesized in the furnace in a $\mathrm{Ar}+\mathrm{H}_{2}$ reducing environment. Carbon nanotube and Si powders were mixed and heat treated in two process cycles for 4 hours each at $1400^{\circ} \mathrm{C}$.

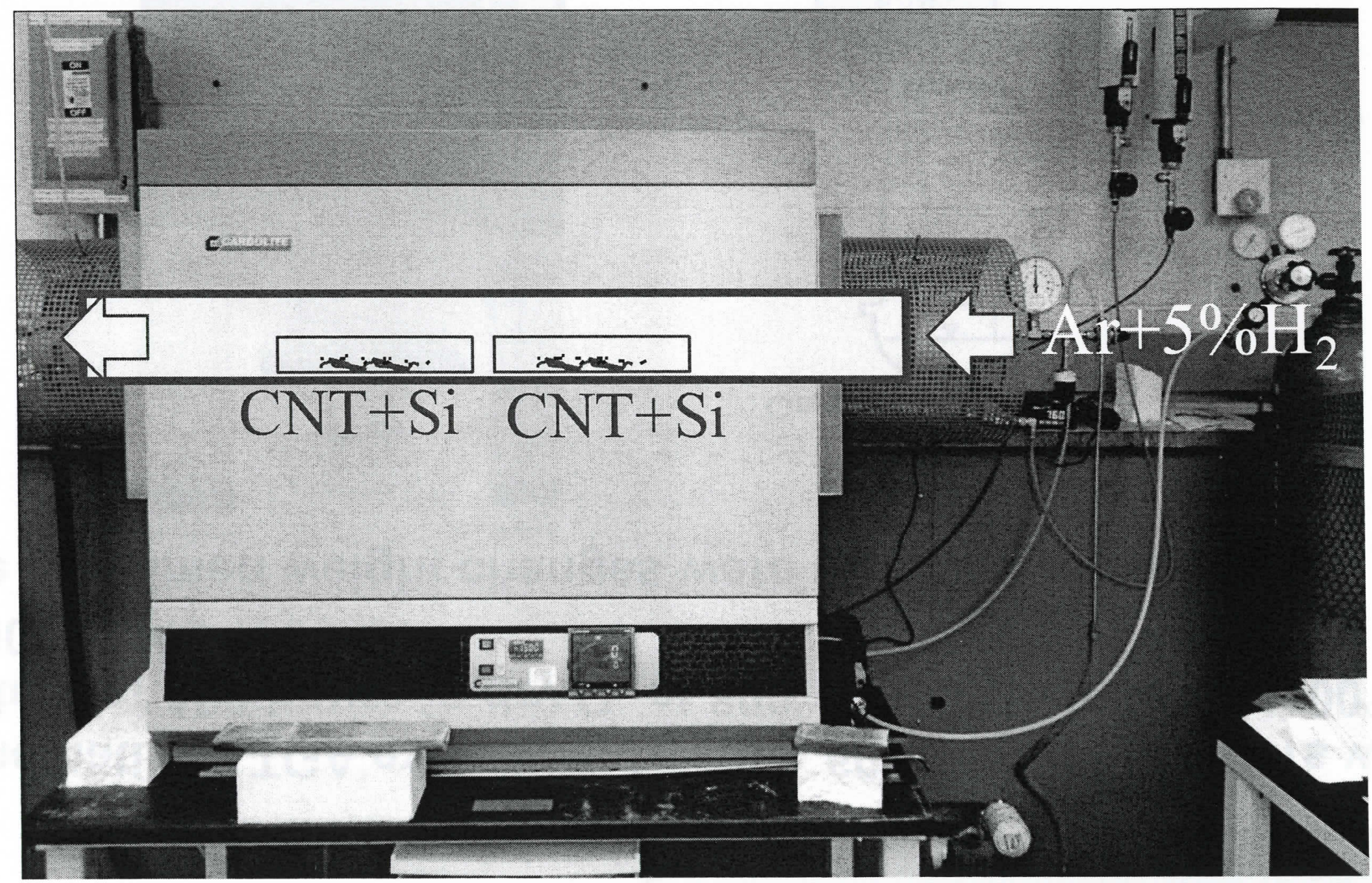




\section{Experimental: Thermogravimetric Analysis}

- Schematic of TGA experiment setup. $60-100 \mathrm{mg}$ of SiCNTs were tested for 100 hours in dry $\mathrm{O}_{2}$ at $800^{\circ} \mathrm{C}, 900^{\circ} \mathrm{C}, 1000^{\circ} \mathrm{C}, 1100^{\circ} \mathrm{C}$, $1200^{\circ} \mathrm{C}$, and $1300^{\circ} \mathrm{C}$.

- The Specimen weight changes were recorded vs. time.
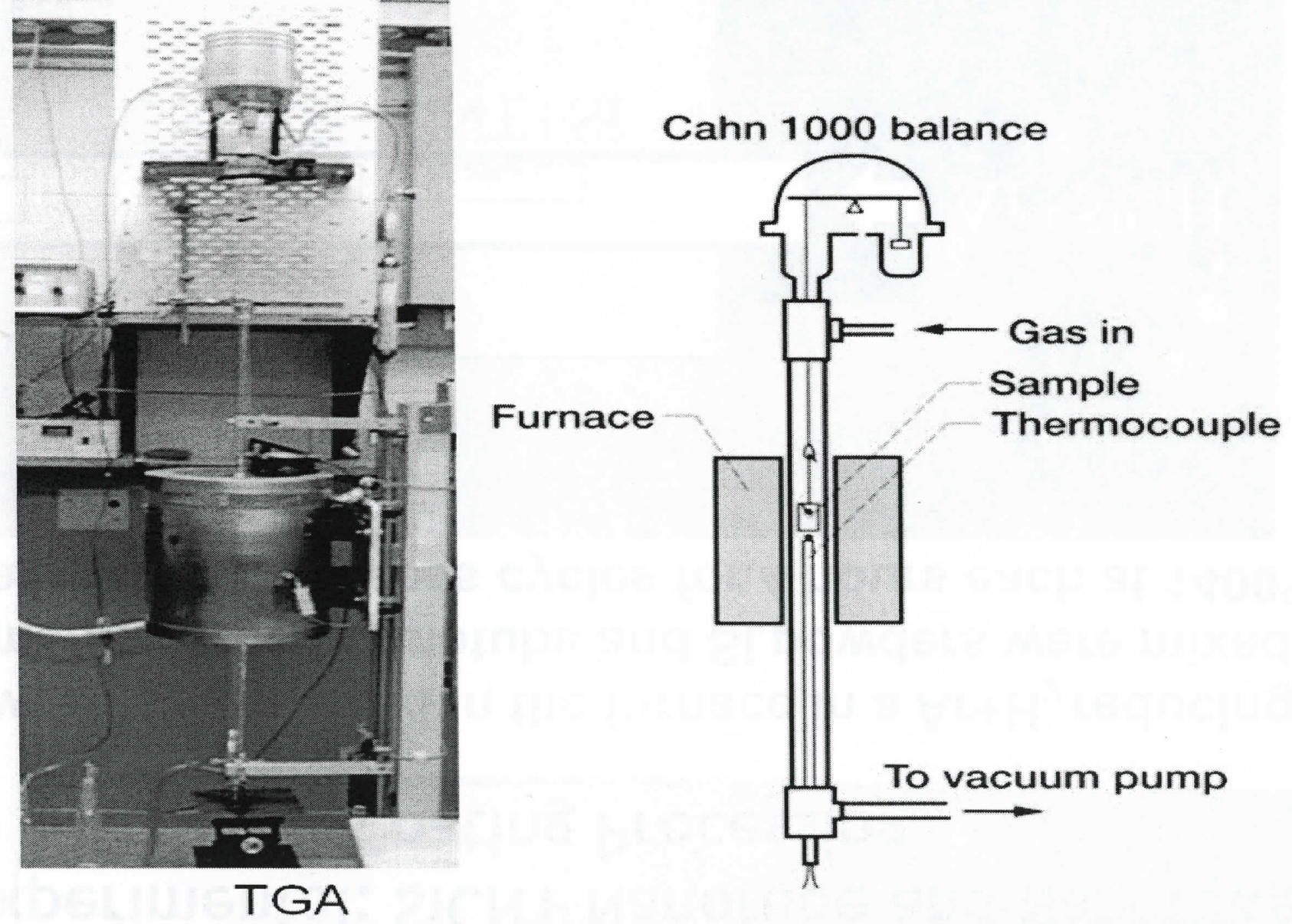


\section{Oxidation Kinetics of SiCNTs - Principles}

- Previous work ${ }^{1,2,3}$ predicted that formation of $\mathrm{SiO}_{2}$ on the nanotube surface follows a parabolic rate law:

$$
\left(\frac{\Delta w}{A}\right)^{2}=K_{p} t+C
$$

$$
\begin{array}{ll}
\Delta \mathrm{w} & =\text { change in weight } \\
\mathrm{A} & =\text { initial surface area }=134500 \mathrm{~cm}^{2} / \mathrm{g} \\
\mathrm{K}_{\mathrm{p}} & =\text { parabolic rate constant } \\
\mathrm{t} & =\text { time } \\
\mathrm{C} & =\text { constant }
\end{array}
$$

- The rate constant $\left(\mathrm{K}_{\mathrm{p}}\right)$ are related to temperature by the Arrhenius equation:

$$
K_{p}=\operatorname{Aexp}(-Q / R T)
$$

$\mathrm{Q}=$ activation energy

$\mathrm{R}=$ gas constant

$\mathrm{T}=$ temperature 


\section{Specific Weight Gain vs. Time for SiCNTs}

- $\quad$ (Specific weight change) $)^{2}$ vs. time is plotted for each temperature. The oxidation behavior appears pseudo-parabolic at $800^{\circ} \mathrm{C}$ up to $1200^{\circ} \mathrm{C}$ for the fiber-like SiCNTs, and $\mathrm{K}_{\mathrm{P}}$ was calculated using equation 1 . For $1000^{\circ} \mathrm{C}$ to $1300^{\circ} \mathrm{C}$, initial shrinking fiber surface area causes the reaction to slow down over time. Only the initial, parabolic portion of each curve was used to calculate $\mathrm{K}_{\mathrm{p}}$.

$$
-800 C-900 C-1000 C-1100 C-1200 C-1300 c
$$

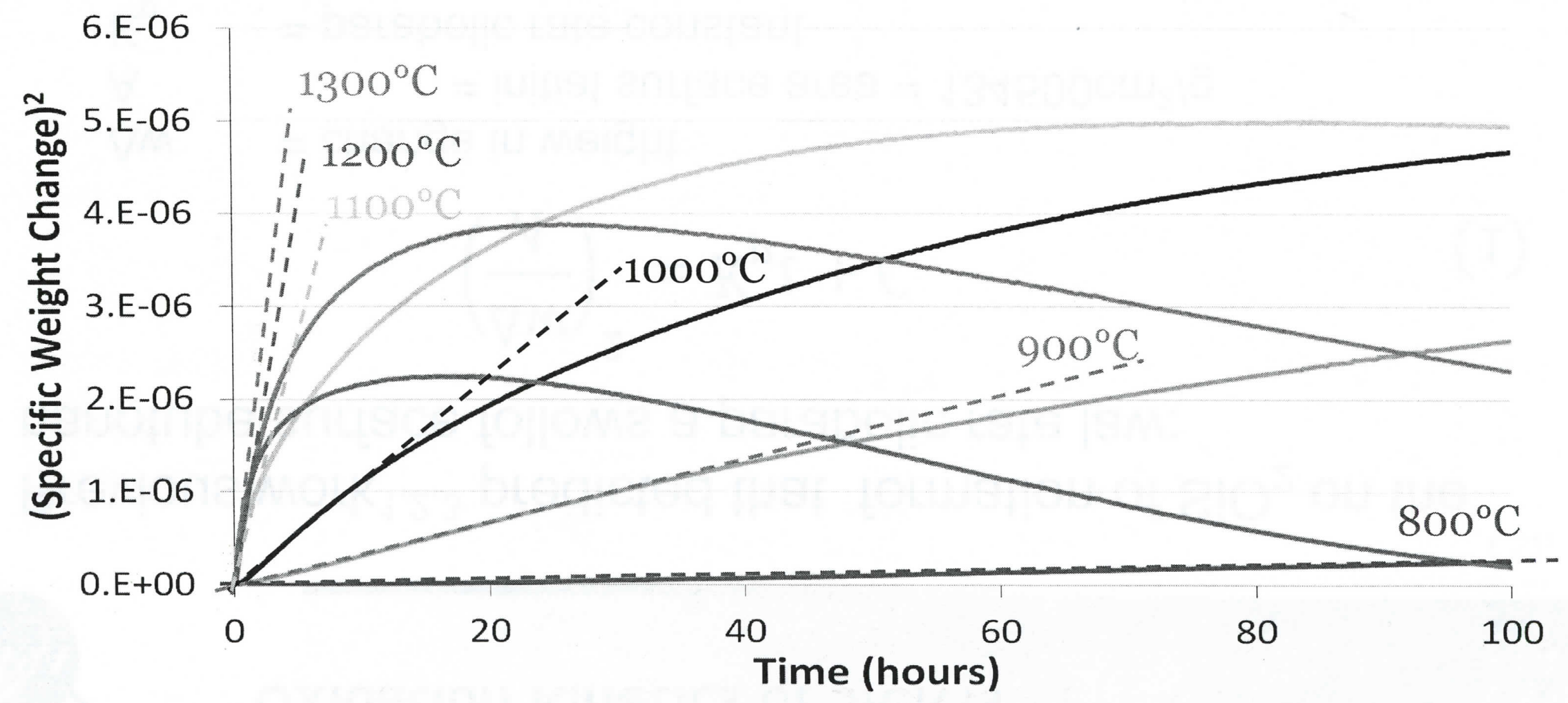




\section{SiCNT Oxidation Activation Energy Based on TGA Tests

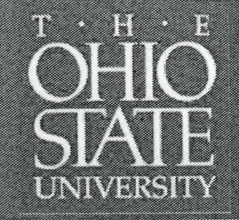

- Equation 2 was used to calculate the activation energy $(Q)$ of $155 \mathrm{~kJ} / \mathrm{mol}$. The graph of Kp vs. 1/T gives a straight line with little deviation, indicating that $Q$ is valid for the $800^{\circ} \mathrm{C}-1300^{\circ} \mathrm{C}$ temperature range.

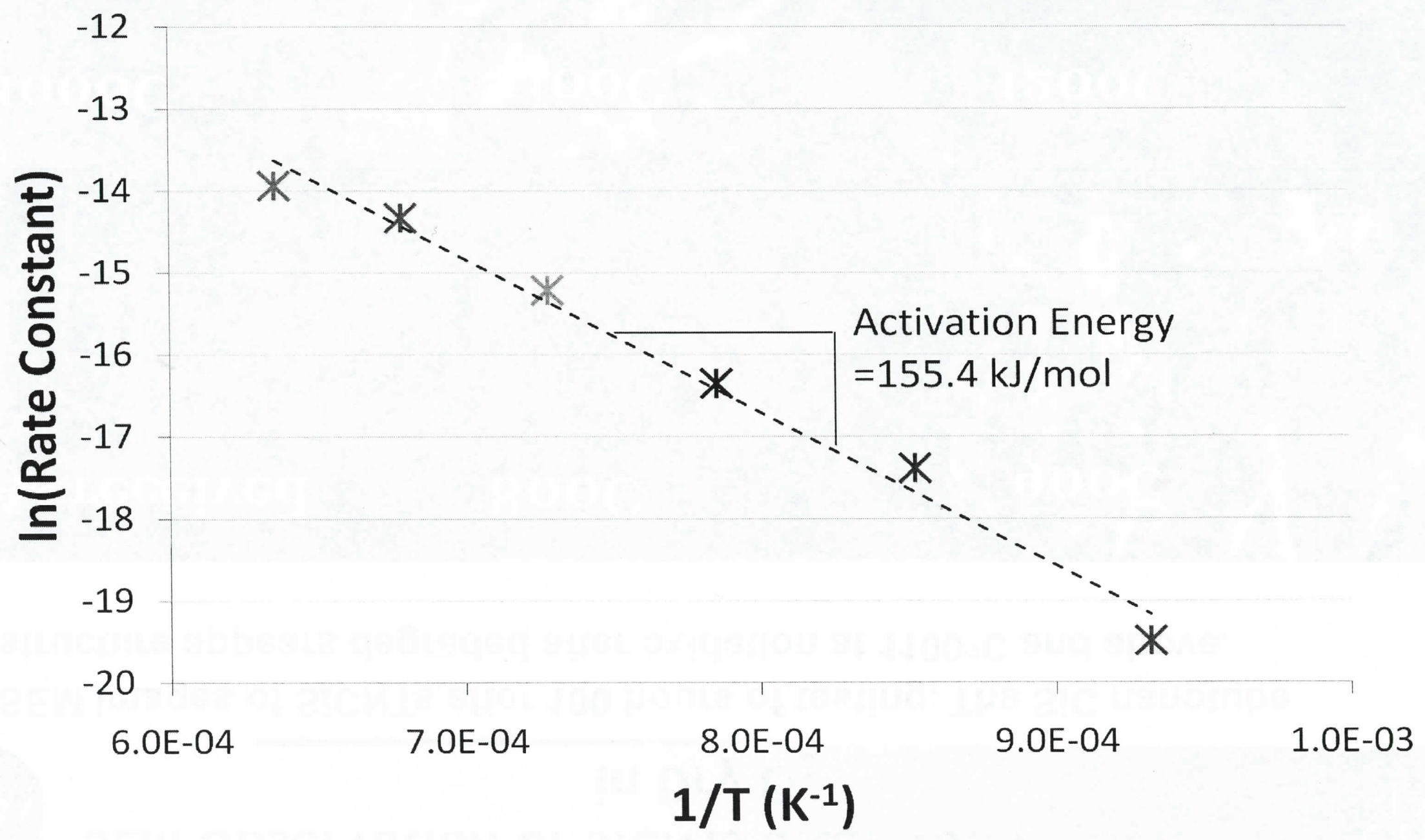




\section{SEM Observation of SiCNTs after $100 \mathrm{hr}$ Oxidation $\mathrm{OHIO}$ in Dry $\mathrm{O}_{2}$

- SEM images of SiCNTs after 100 hours of testing. The SiC nanotube structure appears degraded after oxidation at $1100^{\circ} \mathrm{C}$ and above.

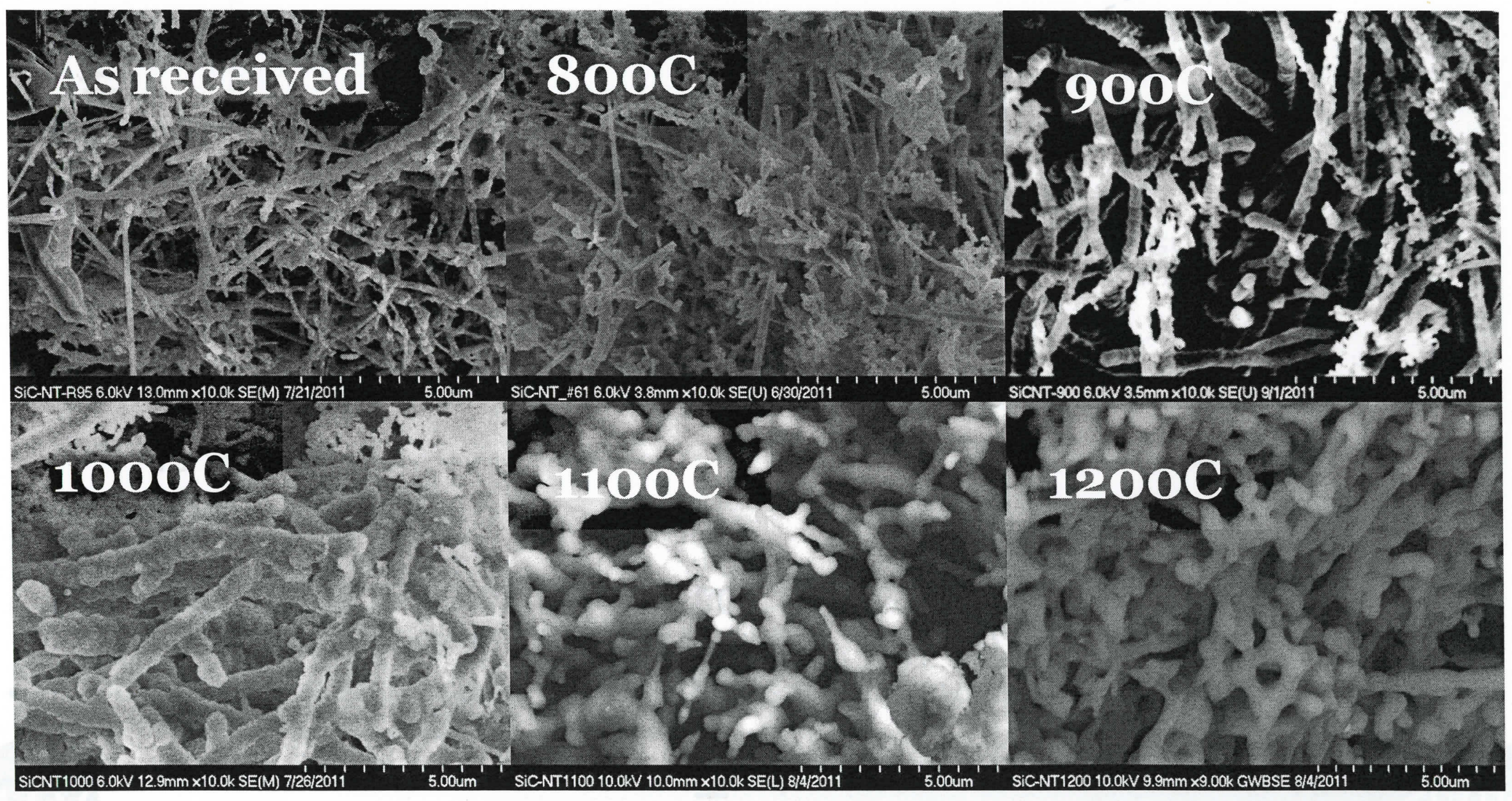




\section{SEM Observation of SiCNTs}

- Box and whisker plot of nanotube diameters vs. TGA temperature. The SiCNTs grew in diameter during each test due to formation of a $\mathrm{SiO}_{2}$ scale.

Nanotube Diameter vs. TGA Temperature

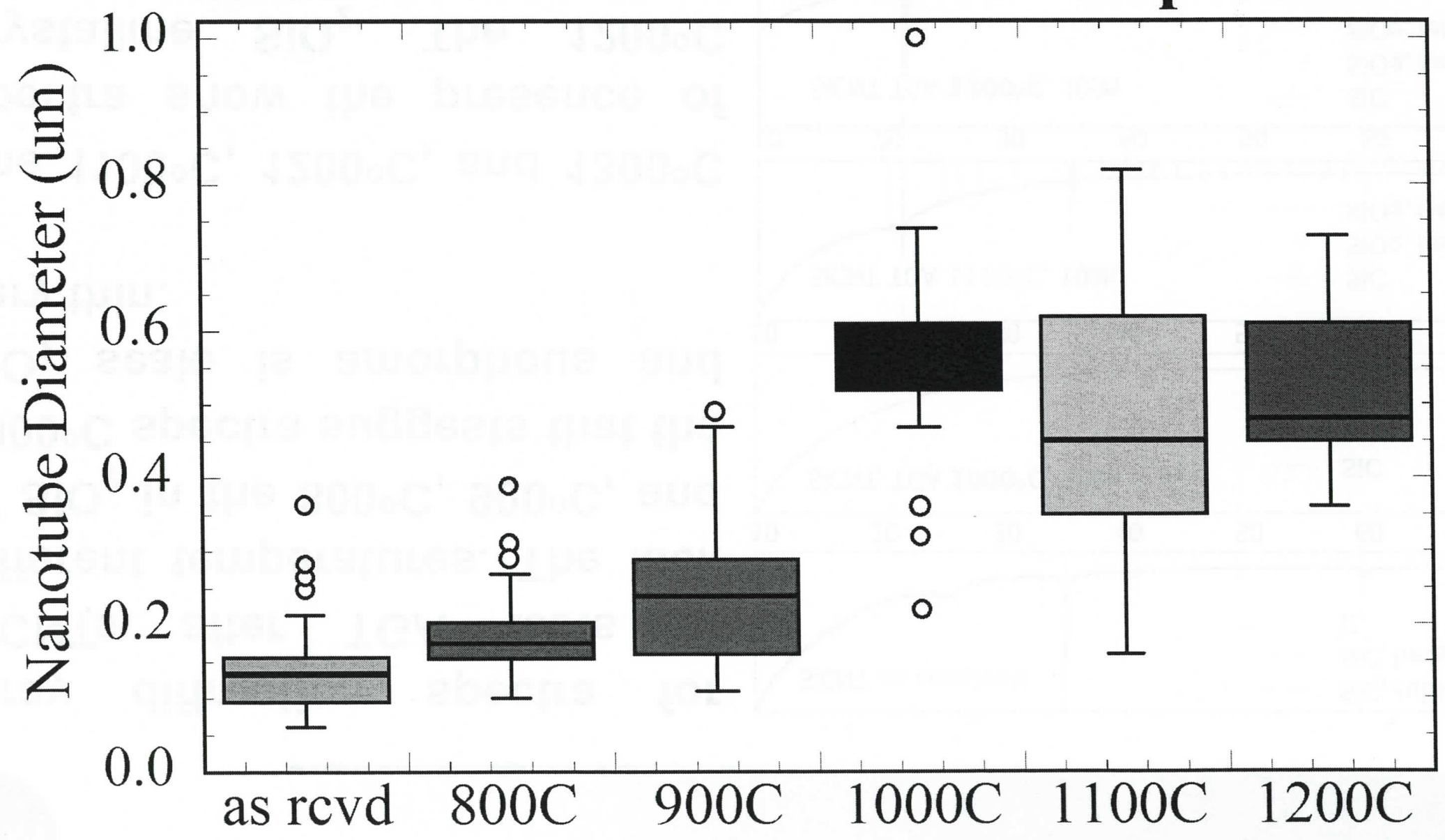




\section{X-Ray Diffraction Results of Oxidized SiCNT}

- X-ray diffraction spectra for SiCNTs after TGA tests at different temperatures. The lack of $\mathrm{SiO}_{2}$ in the $800^{\circ} \mathrm{C}, 900^{\circ} \mathrm{C}$, and $1000^{\circ} \mathrm{C}$ spectra suggests that the $\mathrm{SiO}_{2}$ scale is amorphous and very thin.

- The $1100^{\circ} \mathrm{C}, 1200^{\circ} \mathrm{C}$, and $1300^{\circ} \mathrm{C}$ spectra show the presence of crystalline $\mathrm{SiO}_{2}$. The $1200^{\circ} \mathrm{C}$ sample contains almost no $\mathrm{SiC}$, and the $300^{\circ} \mathrm{C}$ spectrum does not contain $\mathrm{SiC}$, suggesting that all the SiC has been converted to $\mathrm{SiO}_{2}$.
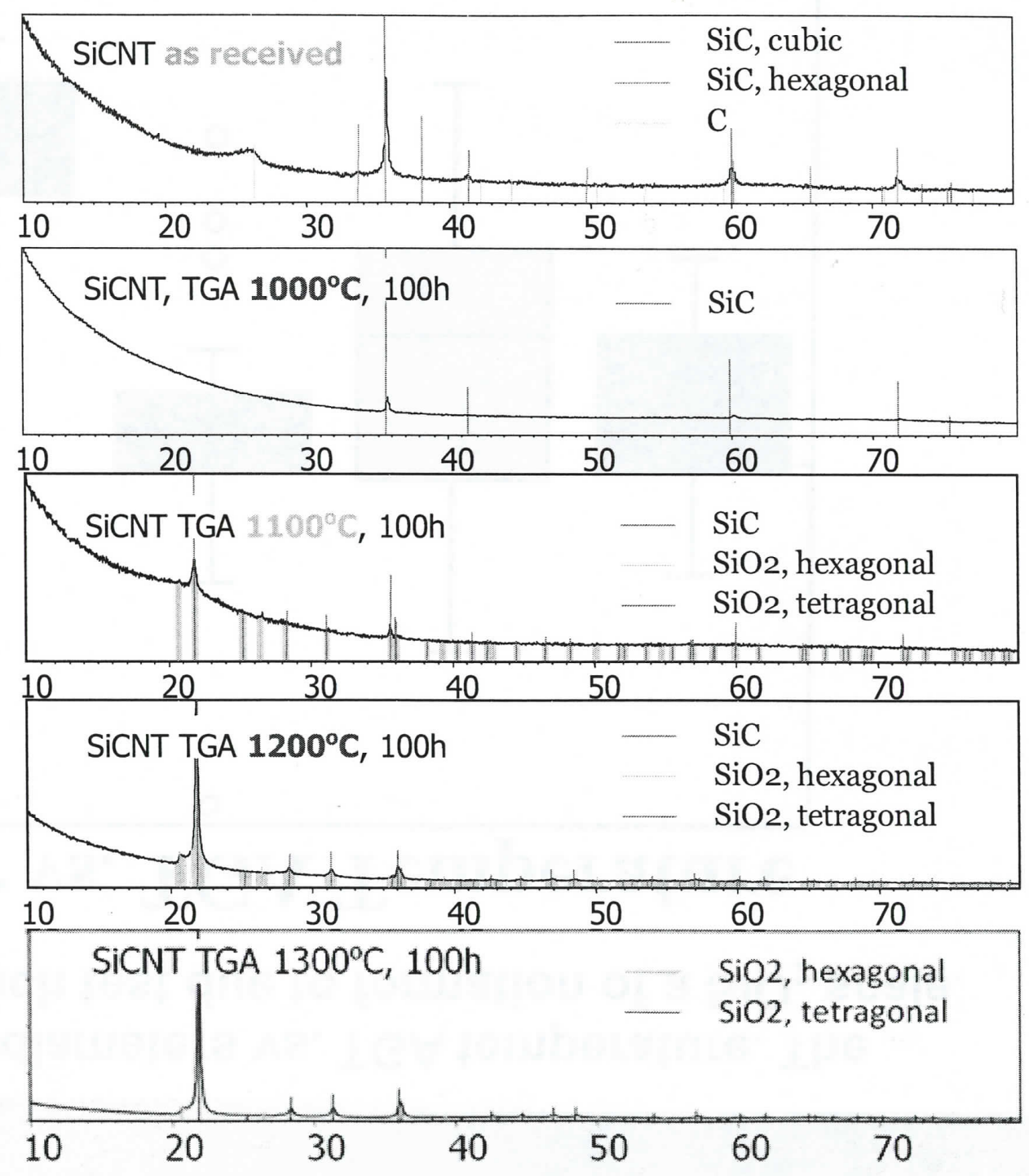


\section{Conclusions}

- SiCNTs exhibit pseudo-parabolic behavior when oxidized in pure $\mathrm{O}_{2}$, following fibrous SiC oxidation behavior.

- The activation energy was $155.4 \mathrm{~kJ} / \mathrm{mol}$ based on TGA studies.

- SiCNTs retained their SiC core and nanotube structure for 100 hours in pure $\mathrm{O}_{2}$ at $800^{\circ} \mathrm{C}-1000^{\circ} \mathrm{C}$. Part of the $\mathrm{SiC}$ is retained at $1100^{\circ} \mathrm{C}$, and almost no SiC remains for the SiCNTs at $1200^{\circ} \mathrm{C}$ and $1300^{\circ} \mathrm{C}$ after 100 hours of oxidation based on x-ray and TGA late stage weight loss results.

- The oxidation behavior suggests that the upper use temperature limit for SiCNTs may be $1200^{\circ} \mathrm{C}$.

- Future work will investigate the effectiveness of a protective coating matrix such as $\mathrm{Yb}_{2} \mathrm{Si}_{2} \mathrm{O}_{7}$ in raising the upper use temperature for SiCNTs. 


\section{References}

1 W. W. Pultz. "Oxidation of Submicroscopic Fibrous Silicon

Carbide," J. Am. Ceram. Soc., 50 [8] 419-420 (1967).

2 Takayuli Narushima, Takashi Goto, and Toshio Hirai. "High-

Temperature Passive Oxidation of Chemically Vapor

Deposited Silicon Carbide," J. Am. Ceram. Soc., 72 [8] 1386-90 (1989).

3 K. L. Luthra. "Some New Perspectives on Oxidation of Silicon Carbide and Silicon Nitride," J. Am. Ceram. Soc., 74 [5] 1095-1103 (1991). 


\section{Acknowledgements}

- This research was funded by the NASA Supersonics and NASA Environmentally Responsible Aviation Projects.

- NASA Lewis' Educational and Research Collaborative Internship Project (LERCIP)

- The authors would like to thank Ms. Joyce A. Dever, Chief of Durability and Protective Coatings Branch, NASA Glenn Research Center, in this research and Internship program.

- The authors are grateful to Don Humphrey for his assistance in performing the TGA experiments. Many Thanks to Ms. Janet B. Hurst and Bob Angus for the helpful discussion and support in the SiC Nanotube and Nanotube coating processing. 